\title{
Comercialização de papel e celulose: o caso da empresa Suzano
}

\author{
Paper and cellulose marketing: the case of the Suzano company
}

Recebido: 21/10/2021 | Revisado: 29/10/2021 | Aceito: 06/11/2021 | Publicado: 07/11/2021

Nícolas de Macêdo Alves

ORCID: https://orcid.org/0000-0002-8107-2991 Universidade Federal de Campina Grande, Brasil

E-mail: alvesnicola660@gmail.com

Isabel Lausanne Fontgalland

ORCID: https://orcid.org/0000-0002-0087-2840

Universidade Federal de Campina Grande, Brasil E-mail: isabelfontgalland@gmail.com

\begin{abstract}
Resumo
O mercado mundial de produtos florestais movimenta mais de 100 bilhões de dólares anualmente. Neste segmento destaca-se a Suzano, empresa brasileira, fundada pelo emigrante ucraniano Leon Feffer, em janeiro de 1924. A companhia paulista, que atua no segmento de papel e celulose, e é considerada uma das dez maiores produtoras de celulose no mundo, além de ser a maior produtora de celulose de eucalipto em escala global. O presente estudo buscou descrever a estrutura produtiva e as inovações sustentáveis fomentadas pela companhia brasileira de papel e celulose, Suzano.
\end{abstract}

Palavras-chave: Papel; Celulose; Inovação; Indústria.

\begin{abstract}
The world market for forest products moves more than 100 billion dollars annually, in this segment Suzano stands out, which is a Brazilian company founded by the Ukrainian emigrant Leon Feffer in January 1924. The company from São Paulo, which operates in the paper and pulp, is considered one of the ten largest pulp producers in the world, in addition to being the largest producer of eucalyptus pulp on a global scale. The present study sought to describe the productive structure and sustainable innovations promoted by the Brazilian pulp and paper company, Suzano.
\end{abstract}

Keywords: Paper; Cellulose; Innovation; Industry.

\section{Introdução}

A partir de 1990, a comercialização de papel e celulose foi apresentando alto desempenho tecnológico. Isto se deveu a vários fatores conjunturais, dentre eles o fato do Brasil ser um país veterano e forte produtor de celulose. Esse setor possui uma participação de 1,3\% do PIB nacional e 6,9\% do PIB industrial. Todos esses percentuais derivam-se das condições climáticas favoráveis e de um enorme volume de investimento direcionado em pesquisa e desenvolvimento florestal, realizados tanto por empresas do setor, quanto por órgãos específicos de pesquisa que permitiram uma trajetória de grande dinamismo tecnológico, com desdobramentos que vão da etapa florestal à logística de escoamento do produto. Importante aqui ressaltar que a indústria de papel e celulose é caracterizada por possuir importantes barreiras à entrada, como por exemplo, grande volume de capital fixo de curto prazo para construção das unidades industriais, e também de longo prazo necessário para manutenção dos investimentos e necessidade de larga extensão territorial para a implementação de (base florestal). No caso brasileiro, o segmento de papel e celulose é caracterizado por ser uma estrutura de mercado de oligopólio competitivo, com alguns grandes grupos detendo grande parcela do mercado. O Índice Herfindahl-Hirschman, que mede o nível de concorrência (e ao mesmo tempo de entropia) de um determinado setor, registrou o grau de $0,06(\mathrm{HHI}<0,15)$, portanto, desconcentrado. Isso posto, avoca- 
se que grandes empresas detêm boa parte da parcela deste mercado, igualmente concorrendo com outras empresas menores, atuando como seguidoras. Dentro dessas grandes empresas que detém boa parcela de mercado, destaca-se a companhia Paulista Suzano, que foi fundada com a chegada do imigrante ucraniano Leon Feffer, em 1924, período que coincide com o início da industrialização brasileira. Com o passar do tempo, em 1961, a Suzano era a primeira empresa no mundo a produzir celulose e papéis com $100 \%$ de fibra de eucalipto em escala industrial. No ano de 1987, a Suzano e Vale do Rio Doce formam, como empreendimento conjunto, a Bahia Sul, atualmente unidade Mucuri, localizada no Sul da Bahia, porém no ano de 2001 a Suzano comprou as ações da Bahia Sul que pertenciam à Vale do Rio Doce e unifica a gestão de todas as suas unidades, desde então, a empresa vem demostrando desempenhos sólidos e com alta capacidade de inovação no mercado de papel e celulose. Nas duas figuras abaixo, contempla-se o histórico da estrutura física da companhia. O registro ao lado esquerdo, representa um dos primeiros anos da empresa e no lado direito uma imagem mais atual da companhia.

Figura 1: Registro antigo da Suzano

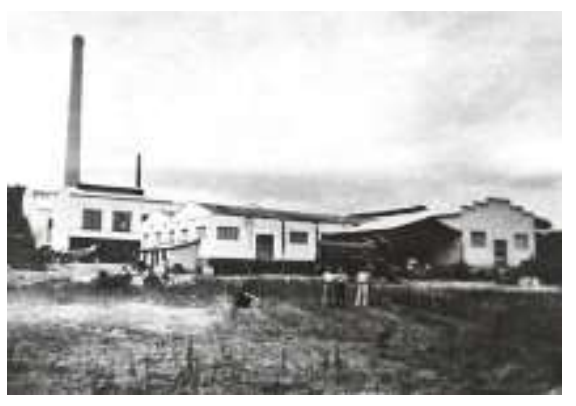

Fonte: Época Negócios
Figura 2: Unidade industrial em tempos atuais.

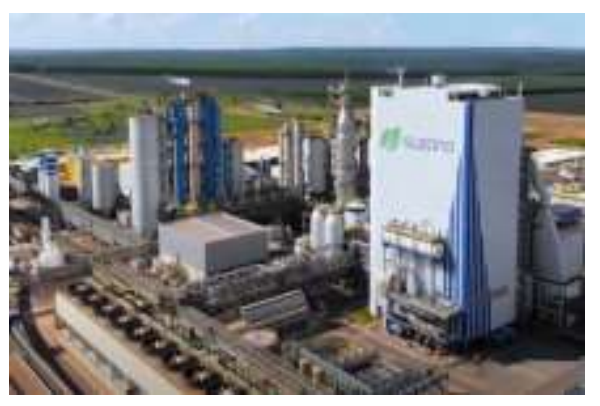

Fonte: Suzano.

\section{Metodologia}

A pesquisa descritiva, de acordo com Gil (2007) é uma análise em profundidade que visa descrever, classificar e interpretar o objeto estudado. A limitação de uma pesquisa descritiva é o alcance de resultados e de análise. Por isso, nesse estudo optou-se pela Metodologia - MEC (metodologia de). A MEC auxilia a considerar o caso, considerando sua validade e a discussão dos resultados. Para evitar esse problema, vários autores, incluindo Yin (2003) e Stake (1995), sugeriram que colocar limites num case pode evitar que vários problemas ocorram. As sugestões sobre como vincular um caso incluem: (a) por tempo e lugar); (b) tempo e atividade (rankin); e (c) por definição e contexto. Os limites não foram de todo observados dado que indicam o que será e o que não será estudado no escopo do projeto de pesquisa. O estabelecimento de limites em um desenho de estudo de caso qualitativo é semelhante ao desenvolvimento de critérios de inclusão e exclusão para a seleção da amostra em um estudo quantitativo. A diferença é que esses limites também indicam a amplitude e profundidade do estudo. Neste estudo em tela estudou-se os aspectos estruturais e inovativos para o desenvolvimento sustentável no mercado de papel e celulose, tomando como o eucalipto (inovação) na empresa Suzano.

\section{Resultados e Discussão}

\subsection{Suzano}

A Suzano conta, atualmente, com sede em Salvador tendo sua sede administrativa em São Paulo. Possui ainda uma ampla unidade instalada na cidade de Três Lagoas (MS), que posteriormente ficou conhecida como a capital mundial da celulose. Além das sedes citadas, a holding possui centros de distribuição espalhadas em dezesseis estados brasileiros e em sete países pelo globo, que são: Áustria, Argentina, Canadá, China, EUA, Israel e Suíça. A empresa igualmente detém o título de 
maior produtora global de celulose de eucalipto, e é uma das 10 maiores empresas de celulose no mundo, com operação em mais de 60 países, sendo importante destacar que a celulose produzida pela Suzano, possui um diferencial, ela é de base renovável e sustentável, que é aplicada em diversos bens do cotidiano como embalagens, livros, papel higiênico, papel para imprimir e escrever etc. A Suzano ultimamente conta com uma estrutura que emprega aproximadamente 35 mil empregados e no ano de 2019, foi consolidada a união entre a Suzano e a Fibria. Após esta união, a marca Fibria foi descontinuada e a Suzano S/A tornando-se a holding do grupo expandindo sua fronteira de produção.

\subsection{Produção}

Em aspectos produtivos, a empresa aumentou consideravelmente seu volume de produção principalmente após a união com a Fibria, sendo capacitada para produzir aproximadamente 12 milhões de toneladas de celulose e 1,5 milhão de toneladas de papel por ano. Atualmente a companhia detém a parcela de $18 \%$ da produção no mercado global e em 2020 , a Suzano exportou 82\% do volume total produzido, sendo a China (50\%), Europa (30\%) e as Américas (20\%) os principais destinos das exportações da empresa. Um dos fatores estimulantes, do alto volume exportado, pela firma no ano de 2020, se deve ao desvantajoso câmbio brasileiro ${ }^{1}$ pós-pandemia. Tal fator, estimulou as exportações da empresa, visto que o câmbio desvalorizado consegue estimular o setor industrial a expandir sua produção para o mercado global, devido ao fato de que os bens transacionáveis nacionais se tornam mais baratos para os demandantes estrangeiros. Na imagem abaixo é mostrado a composição da receita líquida da empresa no último trimestre de 2020, é notório que a celulose é o produto que compõe a maior parcela da receita líquida. Outro fator a se considerar, é que a taxa de absorção dos produtos produzidos no mercado interno é baixa, ou seja, boa parte dos recursos produzidos pela companhia, são exportados ao invés de serem absorvidos no mercado interno.

Figura 3: Receita Líquida.
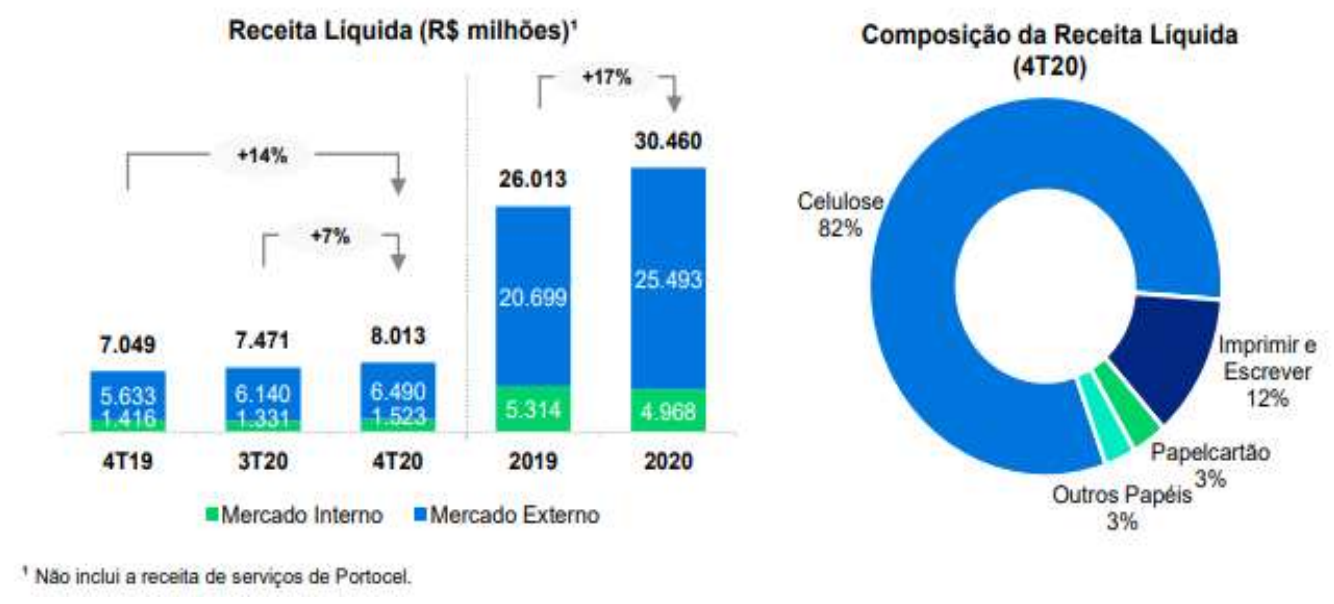

Fonte: "Central de resultados das informações financeiras- Suzano"

O processo de produção de papel e celulose, basicamente é dividido em seis etapas, sendo ilustrado através da imagem abaixo. A primeira etapa é o picador, que é onde se transforma as toras de eucalipto em partículas chamadas de cavacos. A segunda etapa é o digestor contínuo, que é basicamente, um reator pressurizado que possui a função de deslignificação das fibras de madeira. A terceira etapa é a de branqueamento e depuração que é onde são eliminadas as

\footnotetext{
${ }^{1} \$$ US $=$ R\$ 5,99 em 08 de maio de 2020.
} 
impurezas da pasta de celulose. As demais etapas são de secagem, fabricação e acabamento do papel/celulose. Todos estes processos citados envolvem o uso de máquinas e equipamentos de alta tecnologia com a finalidade de atingir economias de escala e escopo.

Figura 4: Processo de produção.

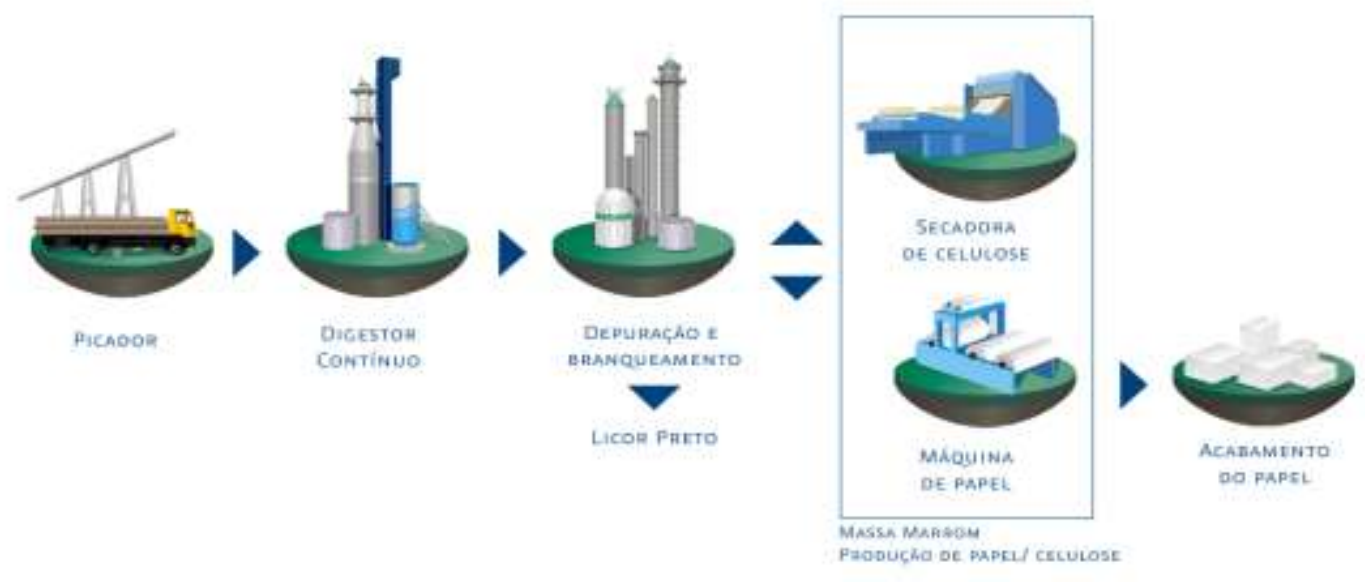

Fonte: "Capacidade e processo de produção" - Suzano.

\subsection{Inovação}

Tendo em vista o enorme crescimento da demanda mundial por produção de fibra, combustível e energia, a Suzano enxergou a oportunidade de investir na sustentabilidade, sendo objeto central das pesquisas da empresa, de forma que cada vez sejam menos utilizados os recursos naturais e fazer com que o segmento de cultivo de árvores tenha a maior taxa de produtividade possível por hectare. Para a realização de tal investimento, a Suzano conta com quatro centros de pesquisa no Brasil. Parte destes centros, se dedica em esforços e estudos para inovação florestal, isto é, tornar os plantios cada vez mais produtivos e sustentáveis em concomitância com a inovação industrial, realizando parcerias com universidades, institutos e startups, com o objetivo de alcançar os melhores patamares em termos de eficácia e sustentabilidade.

\subsubsection{Bioestratégia}

O eucalipto, é um elemento que a empresa acredita que possui enorme potencial para solução sustentável para o mundo. Vale salientar que o eucalipto não faz parte da floresta nativa brasileira, ou seja, seu desmatamento e plantio na base florestal da indústria, não gera desequilíbrios na cadeia ambiental, é um dos motivos por ela ser utilizada em larga escala para fabricação de papel e celulose. Seu plantio pode gerar insumos renováveis para outros segmentos de mercado. Desta forma, são destinados recursos para pesquisa e desenvolvimento direcionado a celulose e outros materiais provenientes do eucalipto, que por sinal, possui diversas possibilidades de aplicação. A Suzano possui linhas de pesquisa nos seguintes materiais: celulose microfibrilada, celulose nanocristalina, celulose solúvel e açúcares, biocompósitos e bio-óleo. O primeiro material citado, a celulose microfibrilada, é utilizada em papeis, tintas, cosméticos e tecidos, sua função é controlar a viscosidade e estabilizar a suspensão de óleos. A celulose nanocristalina é aplicada em óleo e gás, adesivos, tintas e cosméticos. Já a celulose solúvel e açúcares é utilizada na produção de fios têxteis e na indústria química em geral. Se tratando do biocompósito, é aplicado em diversas indústrias, como automotiva, embalagens e bens de consumo. Por fim, e não menos importante, o bio-óleo, que é utilizado em óleo de aquecimento e biopetróleo.

Atualmente, os novos empreendimentos da empresa Suzano estão concentrados em produtos à base de lignina que é 
uma molécula presente na madeira, responsável pelo sustento e proteção das árvores. O objetivo é atender aos mercados de resinas, antioxidantes para borracha e termoplásticos. Além deste empreendimento supracitado, a companhia também está destinando recursos para a nanocelulose, que é um material resistente, leve e transparente obtido da fibra de madeira. Tal biodegradável pode ser usado em aplicações industriais, eletrônicos e cosméticos.

\subsection{Certificações}

As certificações são uma forma de garantia de que a empresa trabalha com comprometimento do desenvolvimento sustentável. Desta forma, a Suzano conta com a certificação reconhecida internacionalmente da Cerflor, que é uma iniciativa nacional de certificação florestal, sendo suas normas elaboradas pela ABNT. Outro atestamento importante possuída pela companhia é a Cadeia de Custódia, que sua finalidade é garantir a proveniência da matéria prima, assegurando a origem da matéria de fonte responsável, socialmente justa e economicamente correto. Além da Cerflor e da Cadeia de Custódia citadas anteriormente, a empresa também conta com o certificado de Manejo Florestal, que é um conjunto de técnicas e mecanismos empregadas em ecossistemas florestais, em conformidade com os mecanismos de sustentação para obter benefício sociais, econômicos e ambientais. A firma conta com o certificado de gestão, que basicamente comprova a capacidade da empresa em fornecer bens e serviços que atendam a demanda dos consumidores, priorizando a qualidade ambiental, assim como a priorização da saúde e segurança dos colaboradores. A Suzano também possui a certificação “Forest Stewardship Council “que abrange as atividades florestais que garante o cumprimento de fatores ambientais, econômicas e sociais até a distribuição do produto por meio da cadeia de custódia e manejo florestal responsável. Por fim, a empresa possui o laudo da ISEGA, comprovando que os papeis atendem os protocolos internacionais para acondicionamento de alimentos. Sendo importante ressaltar também que a produção de papel satisfaz os parâmetros da legislação norte-americana (FDA) e alemã (BRF).

\section{Considerações Finais}

A Suzano, através de seu histórico, toma a dianteira no Brasil e posteriormente no cenário mundial com uma produção agressiva em termos tecnológicos, visando integrar-se de maneira sustentável e arrojada. O aproveitamento da Fibria no seu portfolio representou a alavancagem necessária para o desenvolvimento do ambiente de negócios, tomando o fôlego necessário para introduzir vantagens tecnológicos brasileiras no mercado mundial.

O mix de produtos da Suzano revelou-se, através de seus principais expoentes como: embalagens, papel higiênico, papel para livros e para escrever, produtos essenciais, foco de uma busca sustentável e convivial através da inversão em eucalipto. Essa matéria prima, foi de suma importância, visto que a demanda por produtos sustentáveis é cada vez mais necessária no mercado global. Desta forma, a Suzano compete no mercado mundial, assumindo uma posição importante, na medida em que fomenta inovações coerentes com os novos ordenamentos do milênio no setor de papel e celulose.

Por fim, pode-se sugerir a continuidade deste estudo alertando o uso do eucalipto com valor de sustentabilidade na matriz de recuperação de resíduos. 


\section{Referências}

Barros, A. (2017). Panoramas Setoriais- Papel e Celulose

Esbrasil. (2020), Papel e celulose retrospectiva. Website Esbrasil. https://esbrasil.com.br/papel-e-celulose-retrospectiva-2019/

Fabricio, Processos químicos industriais- Branqueamento de celulose. http://www.dequi.eel.usp.br/ fabricio/branqueamento.pdf

Fontgalland, I. (2021) A MEC- slides, UFCG.

https://revistafbga.com.br/vamos por-no-papel-o-setor-de-papel-e-celulose-em-pauta/

https://web.bndes.gov.br/bib/jspui/bitstream/1408/14241/2/Panoramas\%20Setoriais\%202030\%20-\%20Pape1\%20e\%20celulose_P.pdf

Infasul, O que são picadores de madeira. https://www.infasul.com.br/picadores-de-madeira-tudo-que-voce-precisa-saber-sobre-eles/

Istoedinheiro. (2021), Suzano está de bem com a vida. https://www.istoedinheiro.com.br/suzano-esta-de-bem-com-a-vida/

Kupfer, D., \& Hasenclever, L. (2013) Economia Industrial, Ed, Campus.

REVISTAFGBA. (2020), "Vamos por no papel?" - o setor de papel e celulose em pauta. Website RevistaFGBA.

Simões, L. E. (2021). Com celulose, dólar e demanda sem ceder, ação da Suzano assegura solidez. Website Infomoney. https://www.moneytimes.com.br/comcelulose-dolar-e-demanda-sem-ceder-acao-da-suzano-assegura-solidez/

Static. (2021). Portal da Indústria. https://static.portaldaindustria.com.br/media/filer_public/76/30/763035cf-e3d7-46b6-a165-b6cc862db313/30_cas os_suzano .pdf

Suzano. (2019), Capacidade e processo de produção. https://ri.suzano.com.br/Portuguese/a-companhia/capacidade-e-processo-de-producao/default.aspx

Suzano. (2019), História. https://www.suzano.com.br/a-suzano/historia/

Suzano. (2019), Onde estamos. https://www.suzano.com.br/a-suzano/onde-estamos/

Tradingview. (2021), Indústria de processamento- Papel e celulose. Website Tradingview. https://br.tradingview.com/symbols/BMFBOVESPA-SUZB3/ 